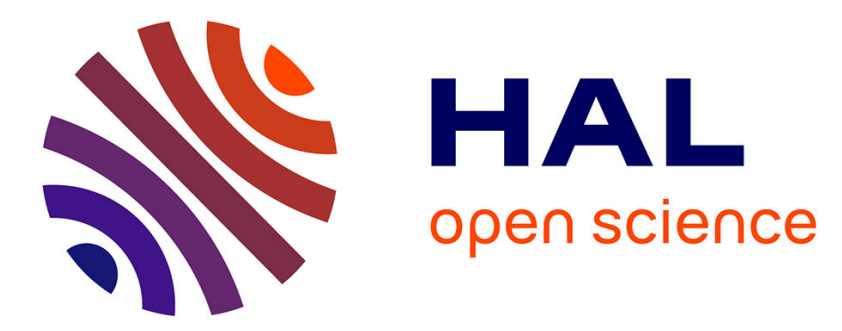

\title{
Niche invasion, competition and coexistence amongst wild and domestic Bolivian populations of Chagas vector Triatoma infestans (Hemiptera, Reduviidae, Triatominae)
}

Frédéric Lardeux

\section{To cite this version:}

Frédéric Lardeux. Niche invasion, competition and coexistence amongst wild and domestic Bolivian populations of Chagas vector Triatoma infestans (Hemiptera, Reduviidae, Triatominae). Comptes Rendus Biologies, 2013, 336 (4), pp.183-193. 10.1016/j.crvi.2013.05.003 . hal-01254147

\section{HAL Id: hal-01254147 \\ https://hal.science/hal-01254147}

Submitted on 14 Jan 2016

HAL is a multi-disciplinary open access archive for the deposit and dissemination of scientific research documents, whether they are published or not. The documents may come from teaching and research institutions in France or abroad, or from public or private research centers.
L'archive ouverte pluridisciplinaire HAL, est destinée au dépôt et à la diffusion de documents scientifiques de niveau recherche, publiés ou non, émanant des établissements d'enseignement et de recherche français ou étrangers, des laboratoires publics ou privés.

\section{(ㅇ)(1) $\$$}

Distributed under a Creative Commons Attribution - NonCommercial - NoDerivatives| 4.0 
Niche invasion, competition and coexistence amongst wild and domestic Bolivian populations of Chagas vector Triatoma infestans (Hemiptera, Reduviidae, Triatominae)

Invasion de niche, compétition et coexistence entre populations boliviennes sauvages et domestiques du vecteur de la maladie de Chagas Triatoma infestans (Hemiptera, Reduviidae, Triatominae)

Frédéric Lardeux ${ }^{\text {a }}$

${ }^{\text {a }}$ Institut de Recherche pour le Développement (IRD), BP 64501, 34394 Montpellier Cedex 5, France.

Tel: + $33(0) 467043224$,

Fax: + 33 (0)4 67542044 ,

E-mail: frederic.lardeux@ird.fr 


\begin{abstract}
The model developed for human parasites by Bottomley et al. [1] has been adapted to the dynamics of triatomines to better understand processes of niche invasion, competition among species and coexistence. In Bolivia, both wild and domestic populations of T. infestans exist. Their ecological niches are normally separated and the two populations do not interbreed, behaving as two distinct species. However, it has been suggested that the two populations may compete, highlighting therefore the potential risk of wild populations invading human dwellings.

The model revealed the importance of the basic reproduction rates $R_{0}$ of triatomine colonies for the risk of invasion. This depends not only on life traits such as survival and fecundity, but also on (1) density-dependence phenomenon which limit triatomine establishment, (2) on house exposure to infection and (3) on the correlation between house susceptibility to domestic T. infestans and house susceptibility to wild T. infestans. Competition and coexistence amongst the two groups of $T$. infestans may occur under particular conditions but are very unlikely.
\end{abstract}

Keywords: Triatominae, invasion, competition, coexistence, domiciliation, Chagas

\title{
Résumé
}

Le modèle mis au point pour les parasites humains par Bottomley et al. [1] a été adapté à la dynamique des Triatomes afin de mieux comprendre les processus d'invasion de niche, de compétition entre espèces et de coexistence. En Bolivie, il existe des populations sauvages et domestiques de Triatoma infestans. Leurs niches écologiques sont normalement séparées, les deux populations ne s'hybrident pas et se comportent donc comme deux espèces distinctes. Toutefois, il a été suggéré que les deux populations pourraient entrer en compétition, soulignant ainsi un risque potentiel d'invasion des habitations humaines par des populations sauvages. Pour l'invasion de niche, le modèle met en évidence l'importance des taux de reproduction de base $R_{0}$ des colonies de Triatomes, qui dépendent non seulement de traits de vies tels que la survie et la fécondité, mais aussi (1) de phénomènes de densité-dépendance qui limitent l'implantation des Triatomes, (2) du taux d'exposition de la maison à l'infection et (3) de la corrélation entre la susceptibilité d'une maison aux populations domestiques de $T$. infestans et la susceptibilité aux populations sauvages. La compétition et la coexistence entre 
les deux groupes de T. infestans sont possibles dans des conditions particulières, mais sont très peu probable.

Mots-Clés: Triatominae, invasion, compétition, coexistence, domiciliation, Chagas 


\section{Introduction}

Chagas disease is an endemic parasitic anthropozoonosis from the American continent caused by Trypanosoma cruzi, a flagellate protozoan which can infect a wide range of wild and domestic mammals as well as humans [2]. Human infections can occur through blood transfusion, congenital transmission, oral route, organ transplant etc., but the most important route by far is through insect vectors (>80\% of the cases) [3]. Insect vectors are hematophagous bugs (Hemiptera, Reduviidae, Triatominae) [4] which acquire the infection by sucking blood from an infected mammal and may retransmit the parasite during the next blood-meal, not through the bite itself but by defecating while sucking blood. The trypanosomes are in the faeces and therefore can penetrate the skin using any mucus membrane or any wound. In the infected host, the disease tends quickly towards a chronic presentation, the parasite causing not immediately apparent but irreversible lesions in the cardiac, digestive and nervous system, frequently leading to the death of the host. Most species of Triatominae occupy predominantly wild habitats that offer shelter from climatic extremes along with easy access to a blood source: bird nests or rodent burrows are common examples. However, some species can also invade and colonise peridomestic habitats such as hen houses or goat corrals, and some have successfully colonised human dwellings. This tendency to colonize houses is important in terms of disease transmission to humans. Transmission is dependent on various factors and for triatomines the most significant are, among others, the blood trophic preference, the rapidity to which the insect can defecate shortly after blood-feeding and therefore leaving $T$. cruzi close to possible body entries [5], and even the density of the insects in a house [6]. However, the most important parameter by far is the tendency of the species to live close to human dwellings (i.e., its degree of domesticity) and therefore to enter frequently in contact with him [7]. Indeed, major vectors of Chagas disease such as Triatoma infestans, Rhodnius prolixus, T. dimidiata or $T$. brasiliensis are amongst the species that have successfully colonized human dwellings in which they now accomplish their life cycle and develop colonies [7]. The "domiciliation process" of Triatominae $[3,8]$ is of major importance in transmission dynamics. Interrelationships between wild (i.e., "sylvatic"), peridomestic and domestic populations of Triatominae (from the same or from different species) should therefore be carefully studied to propose efficient vector control strategies [9 among others]. 
Unfortunately, the existence of interspecific interactions between triatomine species capable of domiciliation is not yet well documented. A particular species has two ways of being successful in colonizing habitats: it may be very good at colonizing open sites, or it may be very good at displacing other species from a given site. Between these two extremes, species may coexist if none of them have too superior a combination of both traits [10]. For triatomines, colonizing open sites, and in particular human dwellings, may occur when humans enter new territories. Such a process is observed in Bolivia for R. stali [11], T. sordida, Eratyrus mucronatus [12] or Panstrongylus rufotuberculatus [13], and in Argentina for T. guasayana [7]. Another scenario would be when a desinsectization campaign empties such an ecological niche. Then some new species may colonize the empty niche from the wild environment $[14,15]$ or the same species may re-colonize the niche from the peridomestic environment that is generally less well controlled by pesticides [16 - 20]. Despite these examples of the struggle for domiciliation, there is no clear record of coexistence of colonies of two different species in the same house. Apart of very infrequent observations [21], only one single species is generally present in one type of ecotope [22 among others]. It seems there exist competitive exclusion, which specifies that two different species cannot share the same ecological niche: one of the two competitors will always win over the other. The loser will either become extinct or will shift towards a different ecological niche by means of evolution or behaviour [23]. This principle might also explain a third scenario of domiciliation which consists of species displacements, such as those observed with $T$. infestans which appear to be a strong competitor to other species [7, 16, 24 - 26]. In Bolivia, T. infestans is well domiciliated and is the main vector of T. cruzi. Domiciliated populations are numerous and widely distributed. There also exist space-limited wild foci which have been identified not only in Bolivia [27 - 31], but also in Argentina [32 - 35], Paraguay [36], Brazil [37] and Chile [38, 39]. In these countries, wild foci of T. infestans were observed in the Chaco region and the Andine cordillera which represent only a small part of the geographic distribution of the species in Latin America. Wild and domestic populations belong to the same species and probably wild populations have had domestic ones as ancestors [29, 40 - 42]. However, unlike for example, for $T$. dimidiata [43], the two entities do not mix. They behave as two different "species" without or with limited gene flow [29, 42, 44 - 46] and can be morphologically distinguished [45, 47]. However, although re-invasion of the domestic environment after insecticide treatment seems to be the fact of residual domestic $T$. 
infestans populations [47 - 50 among others], the possibility that wild populations may reinvade empty human dwellings cannot be discarded [51]. This would be a complication in terms of vector control strategy which therefore would have to take into account the role of wild populations as a potential reservoir for human dwelling reinvasion.

Therefore, it is crucial to better understand (1) how different species (or different populations that do not interbreed) can compete for colonization, (2) if they can manage it, which one is likely to succeed (i.e., what are the key factors for a successful establishment of a species in human dwellings, in particular if another species is already there?) and (3) if two species can coexist in the same ecological niche.

Two hypotheses can be suggested: (1) the two species (or separated "groups") can really share the same ecological niche and in that case invasion, competition and coexistence are part of the natural ecological processes that the two groups may undergo, or (2) the two groups cannot share the same niche because they don't have exactly the same ecological needs. In that case, species cannot interact and there is no possibility of competition or coexistence. The second hypothesis deals, for example, with characteristics such as trophic preferences, microclimatic preferences, behavioural characteristics or any other genetically driven characteristic that would impede one species from colonizing the niche of the other species. This hypothesis will be discussed in a subsequent article for wild and domestic populations of T. infestans.

In the present paper, two initial hypothesis will therefore be taken into account: (1) as stated above, the two groups of $T$. infestans may share the same ecological niche, and (2) the two populations (wild and domestic) are supposed not to interbreed and can thus be considered as two different species. These hypotheses enable competition and therefore, a more general theoretical framework to explore the population dynamics of two competing species of triatomines colonizing human dwellings. In this framework, a new modelling approach for these disease vectors can be proposed: Triatomines can be assimilated to "macroparasites" and human dwellings to "hosts" in a similar manner as for human parasitic diseases modelling [52]. Therefore the mathematical model developed for macroparasites colonizing human populations by Bottomley et al. [1] can be adapted to "triatomines colonizing houses". The model enables to point out the importance of some life traits of the triatomine species for successful invasion, competition or coexistence. The model results although general in the framework of Triatomine dynamics, are discussed in the light of the problem of wild/domestic 
populations of T. infestans in Bolivia and the possible establishment of wild populations in place of domestic ones.

\section{Material and Methods}

The model initial hypothesis is that the two populations, i.e. wild and domestic ones, can live in the same biotopes and do not interbreed. Both populations may colonize a domestic environment (inside houses) or a wild environment as described in [53]: rupiculous or arboreal environments consisting in marsupial or rodent burrows, rocky outcrops, hollow trees etc. Model parameters appear in Table 1 and are explained thereafter.

\subsection{Model for domiciliation of a single species}

A colony of triatomines will be defined as "all the insects from the same mother living in one house". From all the triatomines living in an area, the population with the potential to colonize a house and start a colony are fertilized females. This population is of size $F$. These females may belong to a colony already established in a house and fertilized there, or may come from another house (by flight for example) and may be already fertilized or will be fertilized in this new house. Thereafter, these insects will be referred as "fertilized females" for simplicity. The number of houses that can be colonized is $n$. In one house $i$, there are $C_{i}$ colonies of triatomines of one single species. $F$ and $C_{i}$ are random variables.

The rate of production of new females by a colony is $r$. If the probability that a new-born female develop to the status of "fertilized female" is $P$, then the colonies in the $n$ houses produce fertilized females at a rate $\delta \sum_{i=1}^{n} C_{i}$, where $\delta=r . P$.

In one house, "fertilized females" in colonies are lost either through natural mortality $\mu_{F}$ or through emigration to another house (intending to start a new colony). The rate at which fertilized females are lost through house colonization can be computed as $\sum_{i=1}^{n} \Gamma_{i} F$ where the product $\Gamma_{i} . F$ represents the contact rate of one house $i$ with fertilized females. Houses may harbour large colonies of $T$. infestans, but generally less than the apparent carrying capacity (i.e. number of adequate places to breed) because populations undergo 
strong density-dependence effects which limit the number of triatomines in one house. These density-dependence relationships are related to the availability of hosts for blood-feeding [6, 54 - 58] and hiding places availability [59]. Therefore, the model should take into account a kind of density-dependent establishment, and it can be assumed that the probability of a "fertilized female" surviving and starting a new colony in a house $i$ is lowered by the number of yet established colonies $C_{i}$. This probability can therefore be formulated as $\left(1-\eta C_{i}\right)$, where $\eta$ is the "per colony reduction in probability of starting a new colony". In the model, whenever $\left(1-\eta C_{i}\right)$ becomes negative, it is set to zero.

For model completion, some hypothesis should be formulated on the dynamics of both triatomine colonies and houses. A colony can disappear at a per capita rate $\mu_{C}$ and a house at a per capita rate $\mu_{H}$. However, it is assumed that the number of houses is maintained at size $n$ (i.e., each time a house disappears; it is replaced by a new one that can be infected by triatomines). If a house disappears, the colonies in this house disappear as well. The model can then be formulated in terms of increasing or decreasing number of fertilized females and triatomine colonies following a $n+1$ dimensional Markov process:

- The number of fertilized females increases by one at a rate $\delta \sum_{i=1}^{n} C_{i}$

- The number of fertilized females decreases by one at a rate $\left(\mu_{F}+\sum_{i=1}^{n} \Gamma_{i}\right) . F$

- The number of colonies in one house increases by one at a rate $F . \Gamma_{i} .\left(1-\eta \cdot C_{i}\right)$

- The number of colonies in one house decreases by one at a rate $\mu_{C} . C_{i}$

- The number of colonies in a house is set to 0 at a rate $\mu_{H}$

\subsubsection{Model when house exposure to infestation is identical}

In a first approach it is assumed that each house has the same contact rate with "fertilized females", i.e., $\Gamma_{i}=\Gamma$ for all $i$. Following the analysis of [1], the random variable $F$ (size of the population of "fertilized females") is replaced by its mean $m_{F}$ for simplification and it is therefore possible to derive differential equations for the mean number of "fertilized females" $m_{F}(t)$, the mean number of colonies $m_{C}(t)$ and its variance $\sigma_{C}^{2}(t)$. It is reasonable to consider that the life duration of the "fertilized female" stage (which corresponds to the house-seeking 
phase) is shorter than the duration of its corresponding colony. Therefore $\mathrm{d} m_{F} / \mathrm{d} t$ can be set to zero and the model simplifies to the two following equations for the mean number of colonies and its variance (see [1] for details):

$$
\begin{aligned}
& \mathrm{d} m_{C} / \mathrm{d} t=\delta^{\prime} \cdot m_{C}\left(1-\eta \cdot m_{C}\right)-\left(\left(\mu_{C}+\mu_{H}\right) \cdot m_{C}\right. \\
& \mathrm{d} \sigma^{2}{ }_{C} \mathrm{~d} t=\delta^{\prime} \cdot m_{c}\left(1-\eta \cdot\left(2 \sigma^{2}{ }_{c}+m_{c}\right)\right)+\mu_{c} m_{c}+\mu_{H \cdot} m^{2}{ }_{c}-\left(2 \mu_{c}+\mu_{H}\right) \cdot \sigma^{2}{ }_{c}
\end{aligned}
$$

Where $\delta^{\prime}=\delta . \Gamma . n /\left(\mu_{L}+\Gamma . n\right)$ represents the product of $\delta$, the rate at which a colony produces new "fertilized females", and the probability $\Gamma . n /\left(\mu_{L}+\Gamma . n\right)$ of survival of a "fertilized female" to start a colony.

In a mathematical sense $m_{C}(t)$ and $\sigma_{C}^{2}(t)$ are limiting values of the mean number of colonies and variance when the number of houses tends to infinity. However, these terms also well describe large but finite populations (i.e., >100 houses) as observed in field situations. Epidemiologists define the basic reproduction number $\left(R_{0}\right)$ of a disease as the expected number of secondary infections arising from a single individual during his entire infectious period, in a population of susceptible individuals where there is no immunity and in the absence of interventions to control the infection [60]. The $R_{0}$ concept has also been widely used in ecology where it measures individual reproductive success under ideal conditions (i.e., mean number of offspring produced over the lifetime of an individual) [61]. From these definitions, it emerges that when $R_{0}<1$ each individual (or infected individual if a disease is concerned) produces, on average, less than one new (infected) individual, and therefore the population (or the disease) will not grow. If $R_{0}>1$ the population will grow (or, from the disease's point of view, the "pathogen" is able to invade the susceptible population of hosts). This threshold notion is one of the most important and useful characteristic of the $R_{0}$ concept. This concept can be applied to the development of triatomine colonies (= the "pathogen") in the population of houses (= the "hosts"). In the present triatomine model, the basic reproduction number for the mean number of colonies can be computed from equation (1) as:

$$
R_{0}=\delta^{\prime} /\left(\mu_{C}+\mu_{H}\right)=\left(\delta . \Gamma \cdot n\left(\mu_{L}+\Gamma . n\right)\right) /\left(\mu_{C}+\mu_{H}\right)
$$


When $R_{0}<1$, the triatomine species is unable to establish itself in the houses and therefore, $m_{C}=0$. This value is a stable point. When $R_{0}>1$, the point $m_{C}=0$ is unstable and the number of colonies can increase, up to an equilibrium point where $m_{C}=(1 / \eta)\left(1-R_{0}^{-1}\right)$. The mean number of triatomine colonies is therefore dependent on the basic reproduction number $R_{0}$ and on the strength of density-dependence $\eta$ (i.e., the "per colony reduction in probability of starting a new colony when other colonies are already established"). At this equilibrium, assuming that the rate of disappearance of houses $\mu_{H}$ is much smaller than the other rates, the variance to mean ratio becomes $R_{0}{ }^{-1}$. Indeed, when equating equations (1) and (2) to zero at equilibrium, and equating $R_{0}=\delta^{\prime} /\left(\mu_{C}+\mu_{H}\right) \approx . \delta^{\prime} / \mu_{C}$, straightforward calculations give $\sigma_{C}^{2} /$ $m_{C}=R_{0}{ }^{-1}$. Then, if $R_{0}>1$ (which enables triatomine colonies to grow in number), then $\sigma_{C}^{2} /$ $m_{C}<1$ which implies that the distribution of the number of triatomine colonies across the houses is distributed more evenly than at random. However, field observations prove that triatomine bugs are generally aggregated amongst houses, and therefore some houses harbour more colonies than others [62].

\subsubsection{Model when there is heterogeneity in house exposure to infestation}

The model should therefore be modified to take into account the aggregated distribution of triatomines and therefore to enable $\sigma_{C}^{2} / m_{C}>1$. Several mechanisms can generate such heterogeneity. Amongst them, ecological factors that make some habitats less suitable than others. For example triatomine establishment can be limited if triatomine refuge quantity and quality diminish [62] or when house walls are improved (this can be assimilated to a kind of "immunity" of the houses). Another likely mechanism is heterogeneous exposure of houses to colonization which can also mimic the above mechanisms. Among various factors that can influence heterogeneous exposure, one can think for example to close favourable infested peridomestic habitats that can generate higher domestic exposure in the vicinity $[19,48]$. In the model, heterogeneity can be achieved by enabling a random contact rate of houses with "fertilized females", i.e. replacing in the model the contact rate $\Gamma$ which was fixed, by independent and identically distributed random variables $\Gamma_{i}(i=1$ to $n)$ with mean $m_{\Gamma}$ and

variance $\sigma_{\Gamma}^{2}$ (and therefore a coefficient of variation of the exposure rate of $v_{\Gamma}=\sigma_{\Gamma}{ }^{2} / m_{\Gamma}$ 
which measures the degree of heterogeneity). In that case, model development gives the following equation for the mean number of colonies at stable equilibrium:

$$
m_{C}=\frac{1}{2 \eta\left(v_{\Gamma}^{2}-1\right)}\left(v_{\Gamma}^{2}-1+2 R_{0}^{-1}-\sqrt{\left(v_{\Gamma}^{2}-1\right)^{2}+4 v_{\Gamma}^{2} R_{0}^{-2}}\right), \quad \text { if } v_{\Gamma}>1
$$

and

$$
m_{C}=\frac{1}{2 \eta}\left(1-R_{0}^{-1}\right), \quad \text { if } v_{\Gamma}=1
$$

Where $R_{0}=\delta^{\prime} /\left(\mu_{C}+\mu_{H}\right)$ and $\delta^{\prime}=n . \delta . m_{\Gamma} /\left(\mu_{F}+n . m_{\Gamma}\right)$

Again, when $R_{0}<1$ the triatomine species cannot invade the environment and when $R_{0}>1$, colonies tend to a non-zero equilibrium given by equation (4a) and (4b).

These equations indicate that at equilibrium, the mean number of triatomine colonies is, as before, dependent on (1) the basic reproduction number $R_{0}$ of the colonies, (2) the strength of density-dependence $\eta$, and now also on (3) the degree of heterogeneity $v_{\Gamma}$ through which the aggregative distribution of triatomine colonies within houses can be mimicked.

More precisely, equation (4a) indicates that the mean number of colonies increases as the degree of heterogeneity $\sigma_{\Gamma}$ decreases. In fact no house can harbour more than $1 / \eta$ colonies and even houses with very high rates of exposure cannot have a corresponding high number of triatomine colonies. On the contrary, houses with rates of exposure close to zero will harbour a very low number of colonies. Thus, the mean number of colonies decreases as heterogeneity in exposure increases. The maximum number of colonies $m_{C \max }=(1 / \eta)\left(1-R_{0}{ }^{-1}\right)$ is reached when $\sigma_{\Gamma}=0$, and $m_{C} \approx 0$ when $\sigma_{\Gamma} \rightarrow \infty$.

\subsection{Model for two competing species or populations}

Two species (or two independent populations as it seems to be the case for wild and domestic populations of $T$. infestans) can compete for domiciliation only if they are both able to colonize the same ecotope. Clearly, there exist species of triatomines that cannot invade 
houses because they cannot encounter their ecological preferences in human dwellings. On the contrary, there may exist situations where continuous exchanges between wild and domestic populations take place, as it is the case, for example with Rhodnius prolixus [63]. In the present model it is assumed that the two "species" can evenly colonize both ecotopes. Therefore, if the two species can mix, they may compete for resources such as blood sources [6] or even space $[19,64]$. The latter can be indirectly the consequence of house improvement for example, which limit shelters for $T$. infestans populations.

The model for one single species can be extended to two competing species considering that the probability that a "fertilized female" starts a colony in one house depends, as before, on the number of colonies of its own species (as in the single species model), but also now on the number of colonies of the other species already established. Therefore, one house $i$ may then be colonized at time $t$ by $C_{1 i}$ colonies of species 1 and $C_{2 i}$ colonies of species 2 respectively. The "one species model" can then be modified by replacing $\delta, C_{i}, \Gamma_{i}, \mu_{F}, F, \mu_{C}$ in the transition rates of the Markov process by $\delta_{1}, C_{1 i}, \Gamma_{1 i}, \mu_{F 1}, F_{1}, \mu_{C l}$ for species 1 and $\delta_{2}, C_{2 i}, \Gamma_{2 i}$, $\mu_{F 2}, F_{2}, \mu_{C 2}$ for species 2 . Only the transition rate for increasing the number of colonies by one is modified to take into account species competition, modifying the parameter $\eta$ for each species (per colony reduction in probability of stating a new colony when other colonies are already established), by the parameter $\eta_{j k}(j, k=1,2)$ which represents the effect of species $j$ on the probability of establishment of species $k$.

Therefore, the Markov process for species 1 (and similarly for species 2) is:

- The number of fertilized females (species 1) increases by one at a rate $\delta_{1} \sum_{i=1}^{n} C_{1 i}$

- The number of fertilized females (species 1) decreases by one at a rate $\left(\mu_{F 1}+\sum_{i=1}^{n} \Gamma_{1 i}\right) \cdot F_{1}$

- The number of colonies of species 1 in one house increase by one at a rate $F_{1} \cdot \Gamma_{1 i} \cdot\left(1-\eta_{11} \cdot C_{1 i}-\eta_{21} \cdot C_{2 i}\right)$. Whenever this rate becomes $<0$, it is set to zero. The term $\left(1-\eta_{11} \cdot C_{1 i}-\eta_{21} \cdot C_{2 i}\right)$ represents the probability of establishment of an "infective female" of species 1 in a house where $C_{1}$ colonies of species 1 and $C_{2}$ colonies of species 2 are already present. 
- The number of colonies (species 1 ) in one house decreases by one at a rate $\mu_{C l} . C 1_{i}$

- The number of colonies in a house is set to 0 at a rate $\mu_{H}$

\subsubsection{Model when house exposure to infestation by each species is identical}

Following the same approach as for the one species model, and first considering that exposure to each species is the same for all houses (i.e., $\Gamma_{1 i}=\Gamma_{1}$ and $\Gamma_{2 i}=\Gamma_{2}$ for $i=1$ to $n$ ) and setting $\mathrm{d} m_{F 1} / \mathrm{d} t=\mathrm{d} m_{F 2} / \mathrm{d} t=0$ (i.e., life expectancy of "fertilized females" is much smaller than that of a colony), the mean number of colonies for species 1 and species 2 can be modelled as:

$$
\begin{aligned}
& \mathrm{d} m_{C 1} / \mathrm{d} t=\delta_{1} \cdot m_{C 1}\left(1-\eta_{11} \cdot m_{C 1}-\eta_{21} \cdot m_{C 2}\right)-\left(\left(\mu_{C 1}+\mu_{H}\right) \cdot m_{C 1}\right. \\
& \mathrm{d} m_{C 2} / \mathrm{d} t=\delta_{2} \cdot m_{C 2}\left(1-\eta_{22} \cdot m_{C 2}-\eta_{12} \cdot m_{C 1}\right)-\left(\left(\mu_{C 2}+\mu_{H}\right) \cdot m_{C 2}\right.
\end{aligned}
$$

Where $\delta^{\prime}{ }_{i}=\delta_{i} . \Gamma_{i} \cdot n /\left(\mu_{F i}+n . \Gamma_{i}\right) i=1,2$ is the product of the rate at which potentially "infective females" are produced by a colony and the probability that an "infective female" survives to colonize a house.

Theses equations are symmetrical in regard to species 1 or 2 , and are generalizations of equation (1).

Once again, the behaviour of the system is dependent on the basic reproduction numbers of the two species colonies and the inter- and intra-specific interactions parameters (i.e., the $\eta_{\mathrm{ij}}$ ). For colonies of species $i$, the basic reproduction number is $R_{o i}=\delta^{\prime}{ }_{i} /\left(\mu_{C i}+\mu_{H}\right)$. As in the "one species model", the mean number of colonies of species $i$ will grow if the reproductive number $R_{o i}>1$. If reproductive numbers for both species are $>1$ then two scenarios are possible: (1) the exclusion of one species by the other and therefore the system approaches a single species equilibrium, or (2) coexistence of both species in a mixed equilibrium. As a first approach, the probability of establishment of both species can be considered as dependent of the availability of resources in the house (blood access and space). In other words, the effect of species $i(i=1,2)$ on the establishment of species $i$ or species $j$ is the same. Therefore in the model, $\eta_{11}=\eta_{12}$ and $\eta_{22}=\eta 21$. With this assumption, competitive exclusion and coexistence can be understood by analysis of equations (5) and (6) in the plane 
$\left(m_{C 1}, m_{C 2}\right)$ (Fig. 1). In this plane, points $P 1, P 2, P 3$ and $P 4$ are computed as: $P_{1}=\left(1 / \eta_{21}\right)(1$ $\left.R_{01}{ }^{-1}\right) ; P_{2}=\left(1 / \eta_{22}\right)\left(1-R_{02}{ }^{-1}\right) ; P_{3}=\left(1 / \eta_{11}\right)\left(1-R_{01}{ }^{-1}\right) ;$ and $P_{4}=\left(1 / \eta_{12}\right)\left(1-R_{02}{ }^{-1}\right)$.

$P_{1}$ corresponds to the mean number of colonies of species 2 (i.e., $m_{C 2}$ ) when the isocline $\mathrm{d} m_{C 1} / \mathrm{dt}=0$ crosses the $y$-axis $\left(m_{C 2}\right) . P_{2}$ corresponds to the mean number of colonies of species 2 (i.e., $m_{C 2}$ ) when the isocline $\mathrm{d} m_{C 2} / \mathrm{dt}=0$ crosses the $y$-axis $\left(m_{C 2}\right) . P_{3}$ corresponds to the mean number of colonies of species 1 (i.e., $m_{C l}$ ) when the isocline $\mathrm{d} m_{C l} / \mathrm{dt}=0$ crosses the $x$-axis $\left(m_{C 1}\right) . P_{4}$ corresponds to the mean number of colonies of species $1\left(i . e ., m_{C l}\right)$ when the isocline $\mathrm{d} m_{C 2} / \mathrm{dt}=0$ crosses the $x$-axis $\left(m_{C 1}\right)$.

Figure 1a describes competition of the two species under the assumption $\eta 11=\eta 12$ and $\eta 22=$ $\eta 21$ (equality of effects of species 1 (2) on the establishment of its own species or of species 2 (1)). The two isoclines $\mathrm{d} m_{C 2} / \mathrm{dt}=0$ and $\mathrm{d} m_{C l} / \mathrm{dt}=0$ are parallel and therefore a mixed equilibrium cannot exist. The species with the highest basic reproduction number will exclude the other. In the figure, species 2 will exclude species 1 if $R_{02}>R_{01}$ since this implies that $P_{2}$ $>P_{1}$. This dynamics of competitive exclusion, based on the relative importance of the $R_{0}$ has been well described in other biological systems [65, 66 for example].

Figure $1 \mathrm{~b}$ describes the second scenario, i.e., coexistence. This scenario is possible if species $i$ affects the establishment of its own species more than the other species $j$. In the model, this implies that $\eta_{11}>\eta_{12}$ and $\eta_{22}>\eta_{21}$. In the phase plane analysis, coexistence is achieved when $P_{1}>P_{2}$ and $P_{4}>P_{3}$.

\subsubsection{Model when there is heterogeneity in house exposure to infestation}

However, as for the one species model, heterogeneity in house exposure to infestation should be taken into account. Following [1], the model can be slightly modified and therefore, the variation with time of the mean number of colonies $m_{c i}(\mathrm{i}=1,2)$ is:

$$
d m_{C 1} / d t=\delta_{1}^{\prime} \cdot m_{C 1}\left(1-\eta_{11}\left(\frac{\sigma_{\Gamma 1 c 1}}{m_{\Gamma 1}}+m_{C 1}\right)-\eta_{21}\left(\frac{\sigma_{\Gamma 1 c 2}}{m_{\Gamma 1}}+m_{C 2}\right)\right)-\mu_{c 1}^{\prime} \cdot m_{C 1}
$$




$$
\begin{aligned}
& d \sigma_{\Gamma 1 C 1} / d t=\delta^{\prime}{ }_{1} \cdot m_{c 1} \sigma_{\Gamma 1}^{2}\left(m_{\Gamma 1}^{-1}-\eta_{11}\left(\frac{\sigma_{\Gamma 1 C 1}}{\sigma^{2}{ }_{\Gamma 1}}+\frac{m_{c 1}}{m_{\Gamma 1}}\right)-\eta_{21}\left(\frac{\sigma_{\Gamma 1 C 2}}{\sigma_{\Gamma 1}^{2}}+\frac{m_{C 2}}{m_{\Gamma 1}}\right)\right)-\mu_{C 1}^{\prime} \cdot \sigma_{\Gamma 1 C 1}(8) \\
& d \sigma_{\Gamma 1 C 2} / d t=\delta^{\prime}{ }_{2} \cdot m_{c 2} \sigma_{\Gamma 1 \Gamma 2}\left(m_{\Gamma 2}{ }^{-1}-\eta_{22}\left(\frac{\sigma_{\Gamma 1 C 2}}{\sigma_{\Gamma 1 \Gamma 2}}+\frac{m_{c 2}}{m_{\Gamma 2}}\right)-\eta_{12}\left(\frac{\sigma_{\Gamma 1 C 1}}{\sigma_{\Gamma 1 \Gamma 2}}+\frac{m_{C 1}}{m_{\Gamma 2}}\right)\right)-\mu_{C 2}^{\prime} \cdot \sigma_{\Gamma 1 C 2}
\end{aligned}
$$

With $\delta_{1}^{\prime}=\left[m_{\Gamma_{1}} n /\left(\mu_{F_{1}}+m_{\Gamma_{1}} n\right)\right] \delta_{1}$ and $\mu_{C i}^{\prime}=\mu_{C i}+\mu_{H}$. (i=1, 2). Similar equations can be derived for $m_{c 2}, \sigma_{\Gamma 2 C 2}$ and $\sigma_{\Gamma 2 C l}$ of species 2 .

As in the single species model, the equation (7) describing the colony burden of species 1 in one house (and similarly for species 2 ) now also depends on the covariance between exposure to house infestation and the burden of colonies in houses $\left(\sigma_{\Gamma i \mathrm{Cj}}\right)$.

Coexistence appears when mutual invadability is possible, i.e., when each species can invade an equilibrium where only the other species is present [67]. Conditions of coexistence can therefore be derived from the model as follow: considering equilibrium $e_{1}$ and $e_{2}$ of each species, mutual invadability implies that $e_{1}$ and $e_{2}$ must be unstable to permit invasion of one species by the other. At $e 2$, if few « infective females » of species 1 start (few) colonies and as such disturb the equilibrium, invasion will be successful if after some time the mean number of colonies of species $1\left(m_{C l}\right)$ is growing. In a mathematical sense, $\mathrm{d} m_{C l} / \mathrm{d} t$ (equation (7)) $>0$. At the beginning of the process, the number of colonies of the invading species 1 is small as compared to species 2 and therefore, from equation (7), the rate of increase of species 1 is: $r_{1}=\delta_{1}^{\prime}\left(1-\eta_{21}\left(\frac{\sigma_{\Gamma 1 c 2}}{m_{\Gamma 1}}+m_{c 2}\right)\right)-\mu_{c 1}^{\prime}$

When $r_{1}>0$ the equilibrium 2 is unstable, enabling the establishment of species 1 . In the same way $r_{2}$ determines the stability of equilibrium 1 . The effective reproductive numbers of species 1 and 2 at equilibrium eq2 and eql respectively are: $R_{1}=R_{01} . r_{1}$ and $R_{2}=R_{02} . r_{2}$. where $R_{0 i}=\left(\delta_{i}^{\prime} / \mu^{\prime}\right)(i=1,2)$. Therefore, the condition for coexistence is $R_{1}>1$ and $R_{2}>1$. The two effective reproductive numbers $R_{l}$ and $R_{2}$ can be reformulated taking into account that at $e_{i}(\mathrm{i}=1,2)$, the maximum possible value of the mean number of colonies for species $i$ is attained when $v_{\Gamma i}$ (the coefficient of variation for the rate of exposure of species $i$ ) is zero. 
Then, this maximum value is $m c_{i \max }=\left(1 / \eta_{i i}\right)\left(1-R_{0 i}{ }^{-1}\right)$. Now, introducing $\rho=\sigma_{\Gamma 1 \Gamma 2} / \sigma_{\Gamma 1} \sigma_{\Gamma 2}$ (the correlation between house susceptibility to species 1 and house susceptibility to species 2 ) and developing $r_{1}$ and $r_{2}$, the effective reproductive numbers $R_{1}$ and $R_{2}$ at equilibrium eq2 and $e q 1$ respectively can be expressed as:

$$
\begin{aligned}
& R_{1}=R_{01}\left(1-\eta_{21}\left(\rho \frac{v_{\Gamma 1}}{v_{\Gamma 2}}\left(m_{c 2 \max }-m_{c 2}\right)+m_{c 2}\right)\right) \\
& R_{2}=R_{02}\left(1-\eta_{12}\left(\rho \frac{v_{\Gamma 2}}{v_{\Gamma 1}}\left(m_{c 1 \text { max }}-m_{c 1}\right)+m_{c 1}\right)\right)
\end{aligned}
$$

These effective reproductive numbers appear to be the product of the basic reproductive number $\left(R_{0}\right)$ and a term representing the probability of establishment. This probability depends on the burden of resident triatomines in a house $\left(m_{c m a x}-m_{c}\right)$ and also on the covariance between the burden of the resident species and the susceptibility of the house to the invading species.

These equations indicate that at each respective equilibrium, the effective reproductive numbers are a decreasing function of $\rho$ (the correlation between house susceptibility to species 1 and house susceptibility to species 2). Therefore, intuitively, decreasing the correlation between exposure rates will encourage coexistence.

When heterogeneity is the same for both species (i.e., $v_{l i}=v_{2}=v_{\Gamma}$ ), then the $R_{i}$ are increasing functions of $v_{\Gamma}$ for $\rho<1$ and therefore, increasing the heterogeneity in house exposure to both species of triatome will facilitate coexistence. From these equations, it may also be the case that if $v_{1 i} \gg v_{2}$ (i.e., heterogeneity in house exposure to species 1 is high compared to heterogeneity in house exposure to the other species), then $R_{l}$ will be small because $v_{\Gamma 1} / v_{\Gamma 2}$ > 1 and it will be very difficult for species 1 to establish itself. Therefore, coexistence is unlikely to succeed when the degree of heterogeneity in house exposure greatly differs between the two species of triatomine.

\section{Results and discussion}


A model has been developed to simulate the invasion and colonization of houses by triatomines. The model is a general framework which can describe all situations where one species of triatomine attempts to invade a particular ecotope, or where two species compete to colonize a particular ecotope. The model has been developed in the framework of T. infestans dynamics where individuals may colonize houses, or where two groups (domestic vs wild) may compete or coexist. In that case it was assumed that the two groups behaved as two different species, with no interbreeding.

\subsection{Single species invasion and mean number of triatomine colonies per house}

\subsubsection{Importance of $R_{0}$ of triatomine colonies}

The model captures the observation that the mean number of triatomine colonies in a house is dependent on the basic reproduction number $R_{0}$ of colonies, the strength of densitydependence processes (which govern, for example, access to blood sources and/or shelter for triatomes), and the degree of heterogeneity (i.e., the degree of exposure of houses to infestation by triatomines), through which the aggregative distribution of triatomine colonies within houses can be mimicked. Introducing mechanisms that can generate aggregation is of crucial importance in $T$. infestans dynamics because field observations indicate clearly the existence of such phenomenon $[3,6,54,61,68]$.

\subsubsection{Density dependence processes and heterogeneity of colonization exposure}

The model reveals that if density dependence processes are strong, it will be difficult for a new colony to start. Triatomine dynamics are dependent on the $R_{0}$ value which is (1) directly proportionate to the rate at which a colony produces new « fertilized females » and the probability of survival of « fertilized females » of starting a colony, and (2) inversely proportionate to the per capita rate of disappearance of a colony. Thus, demographic parameters are of importance, in particular, as one might expect intuitively, fecundity and survival $[69,70]$. However, these parameters are offset by density dependence processes. In the model, the mean number of colonies decreases as heterogeneity in exposure increases. Heterogeneity of exposure can be understood in terms of an infested peridomicile or an 
infested nearby house or structure which can be a source of infestation for a house. Indeed, as heterogeneity increases, there are more houses with very high and very low rates of exposure. However, since the number of colonies in a house is limited (as assumed in the model), houses with very high rates of exposure cannot have a corresponding high number of colonies. Thus, in total, the mean number of colonies decreases as heterogeneity increases. In the field, $T$. infestans exhibit such an aggregative distribution with highly infested houses and low infested ones, but always with a limited maximum number of colonies per house. Moreover, when the peridomestic environment is infested (i.e., high exposure rate for the house), and if the "immunity" of the house is low (i.e. if triatomines can find shelter and accessible blood sources inside) [62], the house also hosts domestic populations of triatomines.

A partial concluding remark would be that for a species to invade and colonize an ecotope, the model points out the predominant role of intuitive parameters such as the survival of "infective females", the survival of a colony, a good contact rate (exposure of that ecotope to triatomines) and a good fecundity of colonies producing "infective females".

\subsection{Competition and coexistence of two species}

The model has been extended to two "species" of triatomines (i.e., true species or distinct groups of a same species not interbreeding). The basic hypothesis in the model is that the two "species" have the same ecological needs and therefore, can theoretically share the same niche.

\subsubsection{Competitive exclusion}

In the model, competitive exclusion or coexistence can be described. They depend on the $R_{0}$ values of both species colonies and the values of the $\gamma_{i i}$ and $\gamma_{i j}$, i.e., the "effects" of each species on the establishment of other individuals of its own species and the establishment of individuals of the other species. Generally, the species with the highest basic reproduction number ( $R_{0}$ for colonies) will exclude the other, but coexistence may also occur in particular conditions (see below). Therefore, because $R_{0}$ 's are directly dependent on fecundity and mortality rates, it would be interesting to compare these life traits between the two species. 


\subsubsection{Coexistence}

Coexistence may occur if one species affects the establishment of its own species more than the other species. Indeed the phase plane analysis of fig. $1 \mathrm{~b}$ demonstrated that the two species will coexist if $P 1>P 2$ and $P 4>P 3\left[\right.$ i.e., $\gamma_{11}\left(1-R_{02}{ }^{-1}\right)>\gamma_{12}\left(1-R_{01}{ }^{-1}\right)$ and $\gamma_{22}\left(1-R_{01}{ }^{-1}\right)>\gamma_{21}(1-$ $\left.\mathrm{R}_{02}{ }^{-1}\right)$ ]. The developed formulas indicate that for $R_{01}>1$ and $R_{02} \gg 1$, coexistence will exist when interspecific effects are weaker than intraspecific ones. Interspecific effects might be weaker than intraspecific ones if, for example, there is site segregation between the two species within human dwellings. Such situations have been observed for the peridomestic distribution of Triatoma garciabesi and Triatoma guasayana in north-west Argentina [22]. The two species have slightly different ecotopes in the peridomicile and therefore, coexistence situations have been described. At a larger geographic scale, it has also been described for Rhodnius neglectus and $R$. nasutus [71] and for Triatoma sordida and T. garciabesi [72]. As for $T$. infestans however, it does not seem that $R_{0}$ values are $>>1$, and there is no evidence that one group (domestic for example) may affect its proper establishment more than that of the other group if this latter enters the same site (house, in this case). Even if coexistence is possible, a species may still exclude another one if the $R_{0}$ of the competitively inferior species is sufficiently close to 1 . In that case, for various situations where the $R_{0}$ of the triatomine species are low and species are in low densities, the competitive advantage of one species or the other will vary as $R_{0}$ values change between situations. Then, it might appear that in one site, one competitor will be present exclusively while in another site, it will be the other one.

\subsubsection{The domestic / wild T. infestans populations.}

The model clearly shows that the colonization of houses by wild T. infestans populations is unlikely. Personal field observations by mark-release-recapture technique indicate that $T$. infestans individuals do not move easily between wild and domestic ecotopes, even if they are close (50 $\mathrm{m}$ for example). Therefore, mutual exposure (i.e., exposure of houses to wild triatomines and exposure of sylvatic environment to domestic triatomines) seems to be close to zero while exposure of each type of ecotope by each respective "species" is high and homogenous. If so, the model indicates that (see equations 11 and 12) it is hard for a wild population of $T$. infestans for which host heterogeneity in exposure is high (i.e., a low value of exposure for houses and a high value for a wild environment), to invade the already 
established domestic population where host heterogeneity is relatively low. For example, for the wild species invading a house, equation 11 indicates that its reproductive number will be small because $v_{\Gamma 1} / v_{\Gamma 2} \gg 1$. Invasion will therefore be very hard. Coexistence of wild and domestic populations of $T$. infestans is possible, but very unlikely to occur. Indeed, the model demonstrates that coexistence may occur if one species affects the establishment of its proper species more than the other species when both share the same site. For wild / domestic populations, this is unlikely as each group seems to have slightly different ecological needs and thus occupies different ecological niches. Genetics studies tend to distinguish two groups which do not mix [41]. However, a recent study indicated that gene flows can exist between the two groups [42] but as stated, may represent invasion of sylvatic habitats by domestic populations finding here refuges after insecticide sprayings of houses. In that case, there is no competition, but invasion of an empty niche followed by intra specific movements of dispersion as one might expect. Inversely, if domestic individuals have survived vector control actions and still occupy their houses, the model tends to minimize the possible role of wild population in invading such a "not totally empty" niche.

Wild populations of $T$. infestans are mostly found close to the domestic/peridomestic environment (Brenière, comm. pers.) and the definition of "wild" is indeed difficult. Blood meal sources may help in defining a "wild" population which then feed on wild animals. However, at present, the wild foci of $T$. infestans discovered are mostly under human influence, close to human settlings, except maybe in the Chaco region of Bolivia. For most of these foci, then, it seems that the domestic-peridomestic populations of $T$. infestans have invaded the wild environment and our model can account for such behaviour. If so, a new category of triatomine environment could be proposed: the "PARA- domestic" environment, in addition to the "domestic", "peri-domestic" and "sylvatic" terms yet in use. The paradomestic environment is then under the influence of the domestic-peridomestic environments, with some different characteristics (such as blood sources for triatomines that may be mainly of wild origin) and may permit population to undergo some level of differentiation.

When two groups are considered for coexistence or competition, our model assumption is that they do not interbreed (i.e., are real species). Below this working hypothesis, our model indicates that coexistence of wild and domestic populations of T. infestans is still possible, but very hard to achieve. If so, the colonization of domestic habitats by wild populations is 
unlikely. However, if further studies indicated that gene flows amongst wild and domestic $T$. infestans are significant (i.e., that they interbreed and mix) other models should be used to describe their interactions. Models taking into account source-sink dynamics [73] or better, ecological traps [74 - 75] should then be of great value and would likely explain the present heterogeneities observed amongst wild and close domestic T. infestans populations, such as genes and phenotypic differences or insecticide resistance. If gene flows exist amongst the two groups, then the population is single and the main question would be to identify likely source-sink dynamics where wild groups cannot persist without close domestic ones (and then without threats for vector control) or to identify mechanisms that enable the persistence of wild populations jeopardizing vector control. If so, distant wild populations without any anthropogenic influence should also be found. 


\section{Disclosure of interest}

The author declares that he has no conflict of interest concerning this article.

\section{Acknowledgements}

The author acknowledges the support of (1) the French "Agence Nationale de la Recherche" (ANR), under grant ALTERNATIVE (ANR- 2010 CESA 018 01) "What alternatives to the chemical control of Triatoma infestans ?" and (2) OMS-TDR / IDRC under grant EBS-LAC $\mathrm{n}^{\circ} \mathrm{A} 90281$ "An eco-bio-social approach to implement integrated techniques to control $T$.

infestans in Bolivian poor communities" and (3) Sam Featherston for correcting the English spelling. 


\section{References}

[1] C. Bottomley, V. Isham, M.G. Basañez, Population biology of multispecies helminth infection: Competition and coexistence, J. Theor. Biol. 244 (2007) 81-95.

[2] A.-M. Jansen, A.L.R. Rodrigues, Domestic and wild mammalian reservoirs, in: J. Telleria, M. Tibayrenc (Eds.), American Trypanosomiasis Chagas Disease. One Hundred Years of Research, Elsevier, London, 2010, pp. 248-276.

[3] C.J. Schofield, Triatominae. Biology and control. Eurocommunica Pub. Bognor Regis, UK, 1994.

[4] H. Lent, P. Wygodzinsky, Revision of the Triatominae (Hemiptera, Reduviidae), and their significance as vector of Chagas Disease, Bull. Am. Museum Nat. Hist. 163 (1979) 1-520.

[5] R. Zeledon, Epidemiology, modes of transmission and reservoir hosts of Chagas disease, in: K. Elliot, M. O’Connor, G.E.W. Wolstenholme (Eds.), Trypanosomiasis and Leishmaniasis. Ciba Foundation Symposium 20. Elsevier, North Holland, 1974, pp. 5285.

[6] C.J. Schofield, N.G. Williams, C. Marshall, Density-dependent perception of triatominae bugs bites, Ann. Trop. Med. Parasitol. 80 (1986) 351-358.

[7] J.-P. Dujardin, C.J. Schofield, F. Panzera, Les vecteurs de la maladie de Chagas. Recherches taxonomiques, biologiques et génétiques, Acad. R. Sci. Outre-Mer, Mem in 8, 24 NS (2000) 1-162.

[8] C.J. Schofield, L. Diotaiuti, J.-P. Dujardin, The process of domestication in Triatominae, Mem. Inst. Oswaldo Cruz 94 (1999) 375-378.

[9] S. Gourbière, E. Dumonteil, J.E. Rabinovich, R. Minkoue, F. Menu, Demographic and dispersal constraints for domestic infestation by non-domiciliated Chagas disease vectors in the Yucatan Peninsula, Mexico, Am. J. Trop. Med. Hyg. 78 (2008) 133-139. 
[10] A. Hastings, Disturbance, coexistence, history and competition for space, Theor. Pop. Biol. 18 (1980) 363-373.

[11] A. Matias, J. De la Riva, E. Martinez, M. Torrez, J. -P. Dujardin, Domiciliation process of Rhodnius stali (Hemiptera: Reduviidae) in Alto Beni, La Paz, Bolivia, Trop. Med. Int. Hlth. 8 (2003) 264-268.

[12] F. Noireau, M.-F. Bosseno, R. Carrasco, J. Telleria, F. Vargas, C. Camacho, N. Yaksic, S. Brenière, Sylvatic triatomines (Hemiptera: Reduviidae) in Bolivia : trends toward domesticity and possible infection with Trypanosoma cruzi (Kinetoplastida: Trypanosomatidae), J. Med. Entomol. 32 (1995) 594-598.

[13] F. Noireau, M.-F. Bosseno, F. Vargas, S. Brenière, Apparent trend to domesticity observed in Panstrongylus rufotuberculatus Champion, 1899 (Hemiptera: Reduviidae), Bolivia Res. Rev. Parasitol. 54 (1994) 263-264.

[14] J. Gamboa, Dispersion de Rhodnius prolixus en Venezuela, Bol. Inf. Dir. Malar. Sanid. Ambient. 3 (1962) 262-272.

[15] M.E. Bar, E.B. Oscherov, M.P. Damborsky, Presencia de Triatoma sordida Stal (1859) en ecotopos urbanos de la ciudad de Corrientes, Argentina, Rev. Saude Pub. 27 (1993) $117-122$.

[16] M.B. Aragão, Sôbre a dispersão do Triatoma infestans, Rev. Soc. Bras. Med. Trop. 5 (1971) 183-191.

[17] R.E. Gürtler, R.M. Petersen, M.C. Cecere, N.J. Schweigmann, R. Chuit, J.M. Gualtieri, C. Wisnivesky-Colli, Chagas disease in north-west Argentina: risk of domestic reinfestation by Triatoma infestans after a single community-wide application of deltamethrin, Trans. R. Soc. Trop. Med. Hyg. 88 (1994) 27-30. 
[18] J. Costa, The synanthropic process of Chagas disease vectors in Brazil, with special attention to Triatoma brasiliensis Neiva, 1911 (Hemiptera, Reduviidae, Triatominae) population, genetical, ecological, and epidemiological aspects, Mem. Inst. Oswaldo Cruz 94 (1999) 239-241

[19] M.C. Cecere, G.M. Vazquez-Prokopec, R.E. Gürtler, U. Kitron, Spatio-temporal analysis of reinfestation by Triatoma infestans (Hemiptera: Reduviidae) following insecticide spraying in a rural community in northern Argentina, Am. J. Trop. Med. Hyg. 71 (2004) 803-810.

[20] G.M. Vazquez-Prokopec, M.C. Cecere, D.M. Canale, R.E. Gürtler, U. Kitron, Spatiotemporal patterns of reinfestation by Triatoma guasayana (Hemiptera: Reduviidae) in a rural community of northwestern Argentina, J. Med. Entomol. 42 (2005) 573-581.

[21] H.N. Espinola, R.J. Tonn, E. Moca, J. Jimenez, T.D. Gonzalez, Colonization and competition of Rhodnius prolixus, Rhodnius pictipes, and Triatoma maculata (Hemiptera: Reduviidae, Triatominae) in experimental chicken houses in Venezuela, Bull. Soc. Vector Ecol. 8 (1983) 43-50.

[22] D.M. Canale, M.C. Cecere, R. Chuit, R.E. Gürtler, Peridomestic distribution of Triatoma garciabesi and Triatoma guasayana in north-west Argentina, Med. Vet. Entomol. 14 (2000) 383-390.

[23] G. Harding, The competitive exclusion principle, Science 131 (1960) 1292-1297.

[24] M.E. Bar, E.B. Oscherov, M.F. Damborsky, E.A. Porcel, B. Mabel, Interacción entre poblaciones de Triatoma infestans y Triatoma sordida, Rev. Saud. Publ. 28 (1994) 59-68.

[25] F. Noireau, S. Brenière, L. Cardozo, M.-F. Bosseno, F. Vargas, C. Peredo, M. Medinacelli, Current spread of Triatoma infestans at the expense of Triatoma sordida in Bolivia, Mem. Inst. Oswaldo Cruz 91 (1996) 271-272. 
[26] M.H. Pereira, N.F. Gontijo, A.A. Guarneri, R.V. Maurıcio, M.R.V. Sant'Anna, L. Diotaiuti, Competitive displacement in Triatominae: the Triatoma infestans success, Trends Parasitol. 22 (2006) 516-520.

[27] R.A. Torrico, Hallazgo de Eratyrus mucronatus, infestacion natural de "vinchucas" de cerro y Eutriatoma sordida en Cochabamba, Ann Lab Central Cochabamba 1 (1946) 1923.

[28] M. Borda, Contribución al estudió del T. infestans en Bolivia y su distribución geográfica, Rev. Salud Publ. Boliv. 7 (1967) 6-10.

[29] J.-P. Dujardin, M. Tibayrenc, E. Venegas, P. Maldonado, P. Desjeux, F.J. Ayala, Isozyme evidence of lack of speciation between wild and domestic Triatoma infestans (Heteroptera: Reduviidae) in Bolivia, J. Med. Entomol. 24 (1987) 40.45.

[30] H. Bermúdez, F. Balderrama, F. Torrico, Identification and characterization of wild foci of Triatoma infestans in Central Bolivia, Am. J. Trop. Med. Hyg. 49 (1993) 371.

[31] M. Rojas, L. Emperaire, R.V. Piccinali, R.E. Gürtler, F. Torrico, A.M. Jansen, F. Noireau, Sylvatic Triatoma infestans (Reduviidae, Triatominae) in the Andean valleys of Bolivia, Acta Trop. 102 (2007) 47-54.

[32] S. Mazza, Comprobaciones de Triatoma platensis, Eutriatoma oswaldoi, Panstrongylus seai, y Psammolestes coreodes en la provincia de Santiago del Esteros, todos ellos sin infestación por S. cruzi. Otros datos sobre infestación esquizotripanósica natural silvestre de Triatoma infestans, Prensa Med. Argent. 30 (1943) 1-23.

[33] J.F.R. Berajano, Estado selvático de T. infestans y otros aspectos a tener en cuenta para la eliminación de la enfermedad de Chagas, $2^{\text {nd }}$ J. Entomo-epidemiol. Argent. 3 (1967) 171196. 
[34] M.J. Viana, D.J. Carpintero, Aporte al conocimiento de los triatominos en la Argentina. Primera comunicación, Rev. Museo Argent. Cienc. Nat. Bernardina Rivadavia 5 (1977) $161-174$.

[35] L.A. Ceballos, R.V. Piccinali, I. Berkunsky, U. Kitron, R.E. Gürtler, First finding of melanic sylvatic Triatoma infestans (Hemiptera: Reduviidae) colonies in the Argentine Chaco, J. Med. Entomol. 46 (2009) 1195-1202.

[36] C.J. Velasquez, G. González, Aspectos de la enfermedad de Chagas en Paraguay, Rev. Goiana Med. 5 (1959) 357-373.

[37] M.P. Barretto, F. Ferrioli, Estudos sôbre reservatorios e vetores silvestres do Trypanosoma cruzi. IV.Infecçao natural do Triatoma infestans encontrado em ecotopos silvestres por tripanossomo semelhante ao T. Cruzi, Rev. Inst. Med. Trop. Sao Paulo 6 (1964) 219-224.

[38] A. Bacigalupo, J.A. Segura, A. Garcia, J. Hidalgo, S. Galuppo, P.E. Cattan, First finding of Chagas disease vectors associated with wild bushes in the Metropolitan Region of Chile, Rev. Med. Chil. 134 (2006) 1230-1236.

[39] A. Bacigalupo, F. Torres-Perez, V. Segovia, A. García, J.P. Correa, L. Moreno, P. Arroyo, P.E. Cattan, Sylvatic foci of the Chagas disease vector Triatoma infestans in Chile: description of a new focus and challenges for control programs, Mem Inst Oswaldo Cruz 105 (2010) 633-641.

[40] F.A. Monteiro, R. Perez, F. Panzera, J.-P. Dujardin, C. Galvaõ, D. Rocha, F. Noireau, C. Schofield, C.B. Beard, Mitochondrial DNA variation of Triatoma infestans populations and its implication on the specific status of T. melanosoma,. Mem. Inst. Oswaldo Cruz 94 (1999) 229-238. 
[41] R.V. Piccinali, P.L. Marcet, F. Noireau, U. Kitron, R.E. Gürtler, E.M. Dotson, Molecular population genetics and phylogeography of the Chagas disease vector Triatoma infestans in South America, J. Med. Entomol. 46 (2009) 796-809.

[42] L.A. Ceballos, R.V. Piccinali, P.L. Marcet, G.M. Vazquez-Prokopec, M.V. Cardinal, J. Judith Schachter-Broide, J.-P. Dujardin, E.M. Dotson, U. Kitron, R.E. Gürtler, Hidden sylvatic foci of the main vector of Chagas disease Triatoma infestans: Threats to the vector elimination campaign?, PLoS Negl Trop Dis 5(10) (2011): e1365. doi:10.1371/journal.pntd.0001365.

[43] C.J. Ramirez, C.A. Jaramillo, M.P. Delgado, N.A. Pinto, G. Aguilera, F. Guhl, Genetic structure of sylvatic, peridomestic and domestic populations of Triatoma dimidiata (Hemiptera: Reduviidae) from an endemic zone of Boyaca, Colombia, Acta Trop. 93 (2005) 23-29.

[44] J.-P. Dujardin, M. Tibayrenc, Etudes isoenzymatiques du vecteur principal de la maladie de Chagas Triatoma infestans (Hemiptera: Reduviidae), Ann. Soc. Belge Med. Trop. 65 (1985) 165-169.

[45] J.-P. Dujardin, H. Bermúdez, C. Casini, C.J. Schofield, M. Tibayrenc, Metric differences between sylvatic and domestic Triatoma infestans (Hemiptera: Reduviidae) in Bolivia, J. Med. Entomol. 34 (1997) 544.551.

[46] L. Carlier, M. Muñoz, J.-P. Dujardin, RAPD Protocol for Triatominae, in: C.J. Schofield, J.-P. Dujardin, J. Jurberg (Eds.), Proceedings of the International Workshop on Population Genetics and Control of Triatominae, Santo Domingo de los Colorados, Ecuador. INDRE, Mexico City, 1996, pp. 81-83. 
[47] J.-P. Dujardin, L. Cardozo, C.J. Schofield, Genetic analysis of Triatoma infestans following insecticidal control interventions in central Bolivia, Acta Trop. 61 (1996) 263266.

[48] M.C. Cecere, R.E. Gürtler, D. Canale, R. Chuit, J.E. Cohen, The role of the peridomiciliary area in the elimination of Triatoma infestans from rural Argentina communities, Pan Am. J. Publ. Hlth. 1 (1997) 273-279.

[49] L.A. Cebalos, G.M. Vazquez-Prokopec, M.C. Cecere, P.L. Marcet, R.E. Gürtler, Feeding rates, nutritional status and flight dispersal potential of peridomestic populations of Triatoma infestans in rural northwestern Argentina, Acta Trop. 95 (2005) 149-159.

[50] K. McGwire, E.L. Segura, M. Scavuzzo, A.A. Gomez, M. Lamfri, Spatial pattern of reinfestation by Triatoma infestans in Chancani, Argentina, J. Vec. Ecol. 31 (2005) 1728.

[51] F. Noireau, M.R. Cortez, F.A. Monteiro, A.M. Jansen, F. Torrico, Can wild Triatoma infestans foci in Bolivia jeopardize Chagas disease control efforts?, Trends Parasitol. 21 (2005) 7-10.

[52] R.M. Anderson, R.M. May, Infectious Diseases of Humans: Dynamics and Control, Oxford University Press, Oxford and New York, 1991.

[53] F. Noireau, Wild Triatoma infestans, a potential threat that needs to be monitored, Mem. Inst. Oswaldo Cruz 104 (Suppl. I) (2009) 60-64.

[54] C.J. Schofield, The role of blood intake in density regulation of populations of Triatoma infestans (Klug) (Hemiptera: Reduviidae), Bull. Entomol. Res. 72 (1982) 617-629.

[55] J. Piesman, I.A. Sherlock, H.A. Christensen, Host availability limits population density of Panstrongylus megistus, Am J Trop Med Hyg 32 (1983) 1445-1450. 
[56] D.E. Gorla, C.J. Schofield, Population dynamics of Triatoma infestans under natural climatic conditions in Argentina, Med. Vet. Entomol. 3 (1989) 127.140

[57] R.E. Gürtler, M.C. Cecere, D.N. Rubel, N.J. Schweigmann, Determinants of the domiciliary density of Triatoma infestans, vector of Chagas disease, Med. Vet. Entomol. 6 (1992) 75-83.

[58] M.C. Cecere, R.E. Gürtler, R. Chuit, J.E. Cohen, Factors limiting the domestic density of Triatoma infestans in north-west Argentina: a longitudinal study, Bull. WHO 76 (1998) 373.384

[59] M.C. Cecere, M. Delmi, D.M. Canale, R.E. Gürlter, Effects of refuge availability on the population dynamics of Triatoma infestans in central Argentina, J. Appl. Ecol. 40 (2003) $742-756$.

[60] J.A.P. Heesterbeek, A brief history of $R_{0}$ and a recipe for its calculation. Acta Biotheret. 50 (2002) 189-204.

[61] D. Smith, N. Keyfitz, Mathematical Demography: Selected Papers, Biomathematics, vol. 6, Springer, Berlin, 1977.

[62] C.J. Schofield, Population dynamics and control of Triatoma infestans, Ann. Soc. Belge Méd. Trop. 65 (1985) 149-164.

[63] S. Fitzpatrick, M.D. Feliciangeli, M.J. Sanchez-Martin, F.A. Monteiro, M.A. Miles, Molecular genetics reveal that sylvatic Rhodnius prolixus do colonize rural houses, PLoS Negl. Trop. Dis. 2 (2008): e210. doi:10.1371/journal.pntd.0000210.

[64] J.C. Gomez-Núñez, Desarrollo de un Nuevo método para evaluar la infestación intradomiciliaria por Rhodnius prolixus, Acta Cient. Venezol. 16 (1965) 26-31.

[65] R. Armstrong, B. MacGehee, Competitive exclusion, Am. Nat. 115 (1980) 151-170. 
[66] O. Diekmann, J.A.P. Heesterbeek, Mathematical Epidemiology of Infectious Diseases. Model Building, Analysis and Interpretation, John Wiley \& Son, Ltd, New York, 2000.

[67] V. Hutson, K. Schmitt, Permanence and the dynamics of biological systems. Math. Biosci. 111 (1992) 1-71

[68] C.J. Schofield, Density regulation of domestic populations of Triatoma infestans in Brazil, Trans. R. Soc. Trop. Med. Hyg. 74 (1980) 761-769.

[69] M.B. Castañera, J.P. Aparicio, R.E. Gürtler, A stage-structured stochastic model of the population dynamics of Triatoma infestans, the main vector of Chagas disease, Ecol. Model. 162 (2003) 33-53.

[70] E.B. Oscherov, M.P. Damborsky, M.E. Bar, G. Avalos, B.M. Alvarez, H. Presman, C. Wisnivesky-Colli, Interactions between Triatoma infestans and Triatoma sordida (Hemiptera: Reduviidae) in artificial ecotopes: population growth and age structure, J. Med. Entomol. 38 (2001) 214-217.

[71] T.A. Batista, R. Gurgel-Gonçalves, Ecological niche modelling and differentiation between Rhodnius neglectus Lent, 1954 and Rhodnius nasutus Stål, 1859 (Hemiptera: Reduviidae: Triatominae) in Brazil, Mem. Inst. Oswaldo Cruz 104(8) (2009) 1165-1170.

[72] J.B. Gurgel-Gonçalves, C. Ferreira, A.F. Rosa, M.E. Bar, C. Galvao, Geometric morphometrics and ecological niche modelling for delimitation of near-sibling triatomine species, Med. Vet. Entomol. 25 (2011) 84-93.

[73] H.R. Pulliam, Sources, sinks, and population regulation. Am. Nat. 132 (1988) 652-661.

[74] B.A. Robertson, R.L. Hutto, A framework for understanding ecological gtraps and an evaluation of existing evidence, Ecology 87 (2006) 1075- 1085.

[75] M.A. Schlaepfer, M.C. Runge, P.W. Sherman, Ecological and evolutionary traps. Trends Ecol. Evol. 17 (2002) 474-480. 


\section{Figure captions}

Fig. 1. Phase plane analysis based on eq. (7) for two competing species. The point $P_{1}=$ $\left(1 / \eta_{21}\right)\left(1-R_{01}{ }^{-1}\right)$ correspond to the mean number of colonies of species $2\left(C_{2}\right)$ when the isoclines $\mathrm{d} m_{C 2} / \mathrm{dt}=0$ crosses the $Y$-axis. Equivalently, $P_{2}=\left(1 / \eta_{22}\right)\left(1-R_{02}{ }^{-1}\right) ; P_{3}=\left(1 / \eta_{11}\right)(1-$ $\left.R_{01}{ }^{-1}\right)$; and $P_{4}=\left(1 / \eta_{12}\right)\left(1-R_{02}{ }^{-1}\right)$ are defined as for $P_{1}$.

Fig.1a. corresponds to competition between the two species for a limiting resource, with parameters $\eta_{11}=\eta_{12}$ and $\eta 22=\eta_{21}$ (equality of effects of species 1 (2) on the establishment of its own species or of species $2(1)$ ). Species 2 will exclude species 1 if $R_{02}>R_{01}$ since this implies that $P_{2}>P_{1}$.

Fig. 1b. The two species will coexist if $P_{1}>P_{2}$ and $P_{3}>P_{4}$.

\section{Table captions}

Table 1. Model parameters and variables 
Table 1. Model parameters and variables

\begin{tabular}{|c|c|}
\hline Parameter & Description \\
\hline$n$ & Number of human dwellings considered \\
\hline$F$ & $\begin{array}{l}\text { Size of the population of triatomines with the potential of colonizing a house (i.e., } \\
\text { "fertilized females" which are seeking for a human dwelling) }\end{array}$ \\
\hline$m_{F}$ & Mean number of "fertilized females" \\
\hline$\mu_{F}$ & Per capita rate of mortality of "fertilized females" \\
\hline$C_{i}$ & $\begin{array}{l}\text { Number of triatomines colonies (of one species) in the house } i \text { (burden of } \\
\text { triatomine colonies for house } i \text { ) }\end{array}$ \\
\hline$m_{C}$ & Mean number of triatomine colonies in a house \\
\hline$\mu_{C}$ & Per capita rate of disappearance of triatomine colonies \\
\hline$\Gamma_{i}$ & Contact rate of a house $i$ with "fertilized females" \\
\hline$m_{\Gamma}\left(\sigma_{\Gamma}^{2}\right)$ & Mean (and variance) for contact rate of houses with triatomines \\
\hline$v_{\Gamma}$ & $\begin{array}{l}v_{\Gamma}=\sigma_{\Gamma} / m_{\Gamma} \text { coefficient of variation of the rate of exposure which measures the } \\
\text { degree of heterogeneity of exposure of houses to triatomine colonization }\end{array}$ \\
\hline$r$ & Rate of production of new-born by a colony \\
\hline$P$ & Probability of development of a new-born to the status of "fertilized female" \\
\hline$\delta$ & $=r . P=$ rate at which a colony produces new "fertilized females" \\
\hline$\eta$ and $\eta_{i j}$ & $\begin{array}{l}\text { Density dependent parameter. It is the "per colony reduction in probability of } \\
\text { starting a new colony when other colonies are already established and therefore, } \\
\left(1-\eta \cdot C_{\mathrm{i}}\right)=\text { Probability that a new female survives to start a colony. Therefore, the } \\
\text { maximum number of colonies harbored by a house is } 1 / \eta \text {. } \\
\text { In the two species model, } \eta_{i j} \text { represents the effect of species } i \text { on the probability of } \\
\text { establishment of species } j \text {. Therefore, }\left(1-\eta_{11} C_{l}-\eta_{2 l} C_{2}\right) \text { (and equivalent terms for } \\
\text { species } 2 \text { ) is the probability of establishment of a fertilized female of species } 1 \text { in a } \\
\text { house where } C_{l} \text { colonies of species } 1 \text { and } C_{2} \text { colonies of species } 2 \text { are already } \\
\text { present. }\end{array}$ \\
\hline$\sigma_{\Gamma C}$ & $\begin{array}{l}\text { Covariance between exposure to house infestation and the burden of colonies in } \\
\text { houses }\end{array}$ \\
\hline$\rho$ & $\begin{array}{l}\text { Correlation between house susceptibility to species } 1 \text { and house susceptibility to } \\
\text { species } 2\end{array}$ \\
\hline
\end{tabular}




\section{Figure}
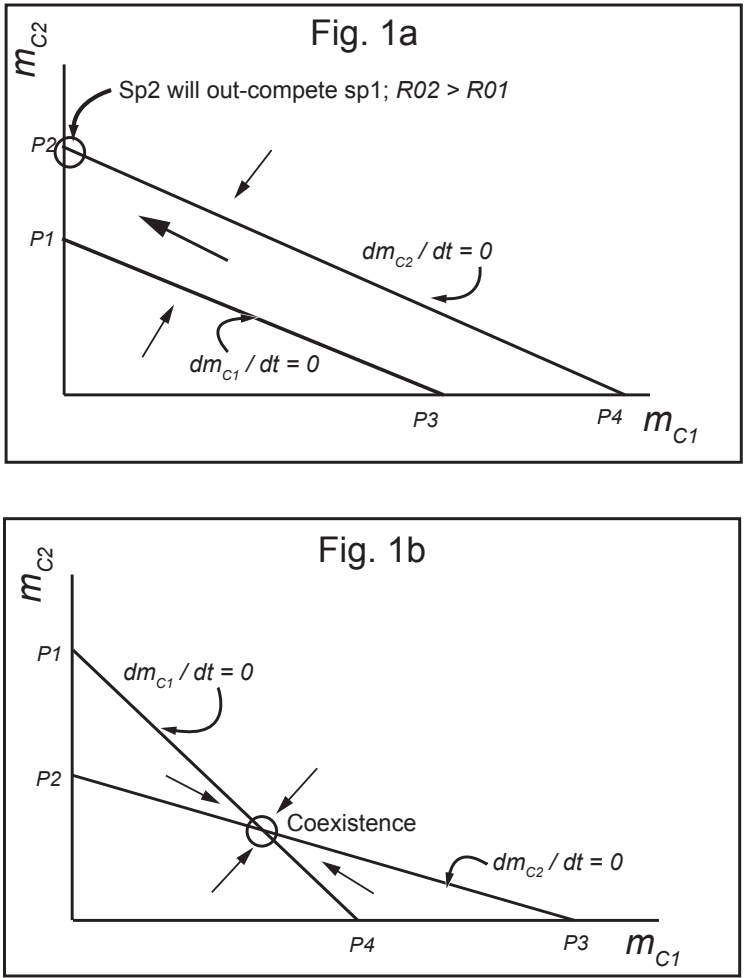